\title{
Comparative Analysis of Helically Grooved and Circumferentially Grooved Labyrinth Seal
}

\author{
Kishore Kumar L, Niranjana Behera \\ School of Mechanical Engineering, Department of Design and Automation, \\ VIT University, Vellore, Tamilnadu-632014, India \\ lkishorkumar06@gmail.com \\ niranjanabehera@vit.ac.in
}

\begin{abstract}
Labyrinth seals are used in turbo-machinery for reducing the leakage of working fluid. The energy lost by the fluid passing through the gap between labyrinth seal and rotor causes the reduction in leakage rate. But the fluid in between the labyrinth seal and rotor induce various forces (radial and tangential forces). These forces can be represented by certain numbers of coefficients, such as stiffness and damping coefficients. In this work, a comparative analysis has been carried out between a helicallygrooved and a circumferentially-grooved labyrinth seal using a CFD program Fluent. Parameters such as fluid forces, leakage and rotordynamic coefficients for both the labyrinth seals are calculated. Modelling and analysis have been performed with seal-rotor configurations having different eccentricity ratios $(0.1$, $0.2,0.34,0.4,0.5$ and 0.68 ). Leakage and rotordynamic coefficients have been calculated and compared for the two seals under different inlet pressures, rotor speed, etc. The calculated leakage was same for both the labyrinth seals, but the calculated rotordynamic coefficients were different.
\end{abstract}

Keywords - Helically-grooved, circumferentially-grooved, stiffness coefficient, damping coefficient, labyrinth seal

\section{INTRODUCTION}

Labyrinth seals are one type of non-contacting seals which are used in turbomachinery components such as turbines, compressors and pumps. The main purpose of using the labyrinth seals is to reduce the leakage of working fluid through the gap between the rotor and the stator. Labyrinth seals are classified into two types, straight-through labyrinth seal and stepped labyrinth seal. In order to reduce the leakage the labyrinth seals are carefully designed. The leakage may be occurring less at a particular time, but when used for longer period of time it may ruin the efficiency of the whole system. Hence accurate prediction of leakage through the labyrinth seal becomes important.

On the other hand, labyrinth seal being a non-contact seal causes some instability problems due to the presence of eccentricity. The instability is due to the fluid forces which are created due to the eccentricity of shaft from the center of stator. These forces tend to move the rotor away from the centre of stator which eventually creates the instability. Hence it is essential to investigate on the instability caused due to labyrinth seals.

Many researchers have worked on leakage analysis through seals. Works of few researchers have been discussed here. The authors in [1] experimentally recorded the variation in the discharge because of pressure ratio and Reynolds number over the labyrinth seal used in jet engine. The authors in [2] conducted leakage tests experimentally on labyrinth seal for different tooth profiles, tooth thickness and eccentricities. They concluded that increasing the tooth thickness by two times the leakage reduced by $26 \%$. The authors in [3] have analysed two different labyrinth seals of different configuration and clearance to record the variation in leakage. The authors in [4] have investigated thee streamline pattern and pressure distribution for a two dimensional model. They proposed that the leakage characteristic of a labyrinth seal is directly proportional to the inlet pressure. The authors in [5] analysed the annular seal with helical groove for different helix angles and the leakage characteristics of the different angles were discussed. The authors in [6] have proposed a new radial annular rim seal (RARS) as a replacement for traditional labyrinth rim seal (LRS). They have concluded that the annular rim seal can reduce the leakage velocity compared to the traditional labyrinth seal. The authors in [7] considered wear of labyrinth seal of two different materials and concluded that with increase in wear the leakage increases.

In the literature it has been found that many researchers have worked on rotordynamic analysis of seals, but works of few researchers have been discussed here. The authors in [8] calculated the dynamic characteristics of the interlock and labyrinth seal experimentally using appropriate test apparatus. The authors in [9] calculated leakage and rotordynamic coefficients for straight-through labyrinth seal by solving continuity and momentum equations. The author in [10] wrote continuity and circumferential momentum equations for compressible flow in a stepped labyrinth seal. He calculated rotordynamic coefficients by solving these equations. The authors in 
[11] have analysed the labyrinth seals used in compressor and steam turbine. The analysis was carried out using ANSYS CFX Tascflow software. In their analysis the mesh density study is vital for calculating the rotordynamic coefficients and forces. Here they have considered a three dimensional model study with eccentric rotor and compared the obtained values with the bulk flow analysis program DYNLAB. They have concluded that the bulk flow analysis program DYNLAB gives pessimistic results. The authors in [12] conducted static analysis using CFD for different cavity models like triangular, square, etc. in order to study the variation in pressure drop and cavitation. The authors in [13] calculated experimental values of direct and cross-coupled stiffness for brush seals. They also calculated stiffness by integrating circumferential pressure distribution in seal cavities and the error between experimental and predicted data is low. The authors in [14] calculated rotordynamic coefficients for annular seal with a large aspect ratios using CFD. They also calculated the coefficients bulk flow method and finite difference method. Value of coefficients predicted by CFD method was highest. The authors in [15] compared the leakage and rotordynamic characteristics between a slant-tooth and a straight-tooth labyrinth seals by conducting experiments at different pressure ratios and different rotor speed. The authors in [16] numerically predicted the rotordynamic coefficients of an annular plain gas seal using CFD and compared with the values obtained by bulk flow method. CFD predicts better in accuracy as compared to the bulk flow method. The authors in [17] conducted CFD transient analysis to compare the rotordynamic characteristics between a fully partitioned damper seal and a labyrinth seal. They have also predicted the effect of inlet pre-swirl over the cross coupled rotordynamic characteristics.

Analysis of seals can be carried out through experiment, analytical and numerical work. Numerical models using CFD are suitable as compared to the cost time involved in the experimental setup. In this work, modelling and simulation have been performed for two different types of seals: helically-grooved and circumferentiallygrooved labyrinth seal using CFD. With the help of commercial FLUENT software various parameters like leakage and rotordynamic coefficients of the two compressor labyrinth seals have been predicted and compared.

\section{MODELING AND SIMULATION}

\section{A. Modeling of helically-grooved and circumferentially-grooved labyrinth seal}

The fluid region within the gap between the stator (labyrinth seal) and rotor have been modelled using Solidworks modelling software. The geometric center of the rotor and the stator do not lie in same position. The distance between the geometric centers is known as eccentricity. So the region occupied between stator and rotor will be different for different eccentricities. A number of models have been created for both helicallygrooved and circumferentially-grooved labyrinth seals with different eccentricities.

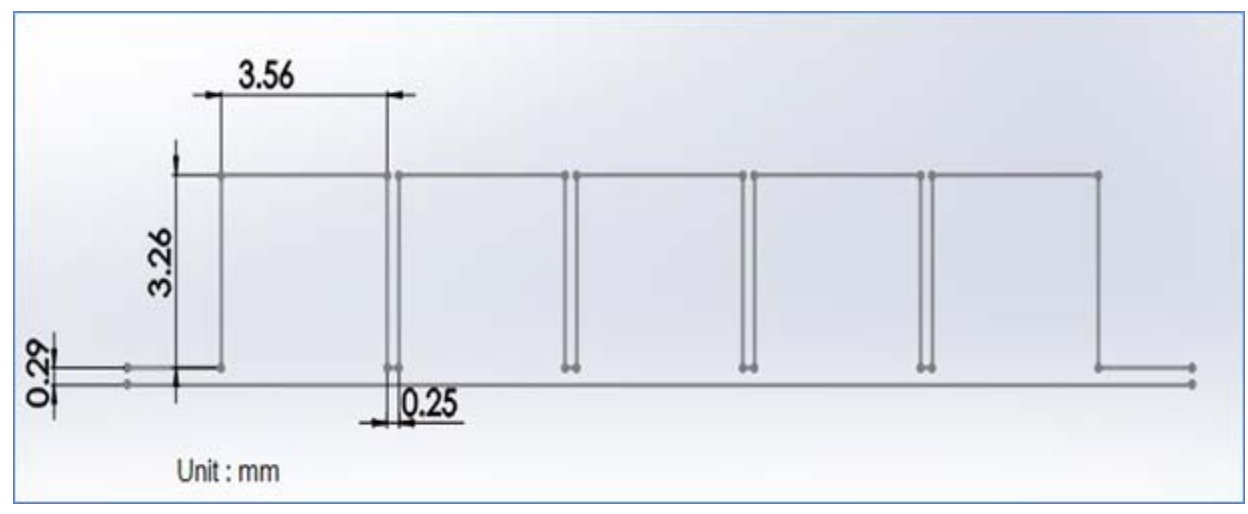

Fig. 1. Dimensions of labyrinth seal

The dimensions of the helically-grooved labyrinth seal have been shown in the Fig. 1. The seal dimensions and input parameters for simulation have been chosen from the research work presented by Hirano et al. [11]. The two dimensional view of the helically-grooved labyrinth seal is shown in Fig. 2.

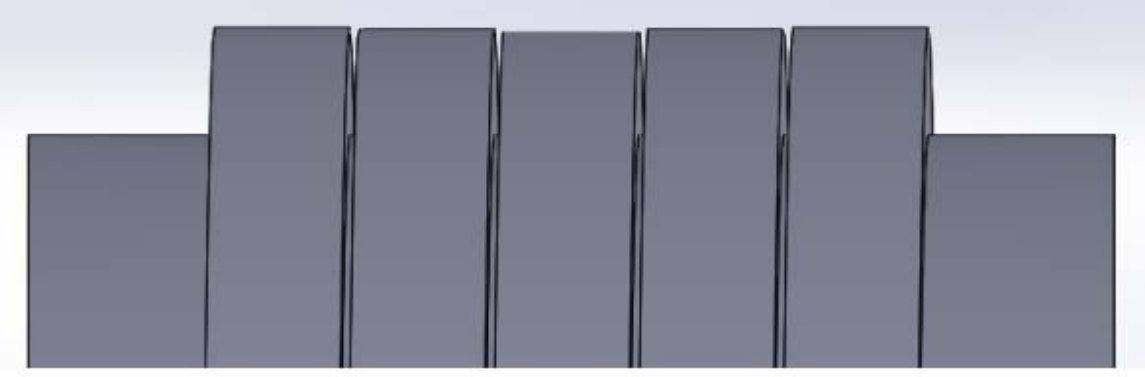

Fig. 2. 2D view of helically-grooved labyrinth seal 
For the comparative analysis, the configurations of the both helically-grooved and circumferentially-grooved labyrinth seals must be identical in terms of dimensions. The dimensions of circumferentially-grooved were similar (w.r.t. height of cavity, width of cavity and clearance between seal and rotor) to helically grooved labyrinth seal. The two-dimensional view of the circumferentially-grooved labyrinth seal has been shown in Fig. 3.

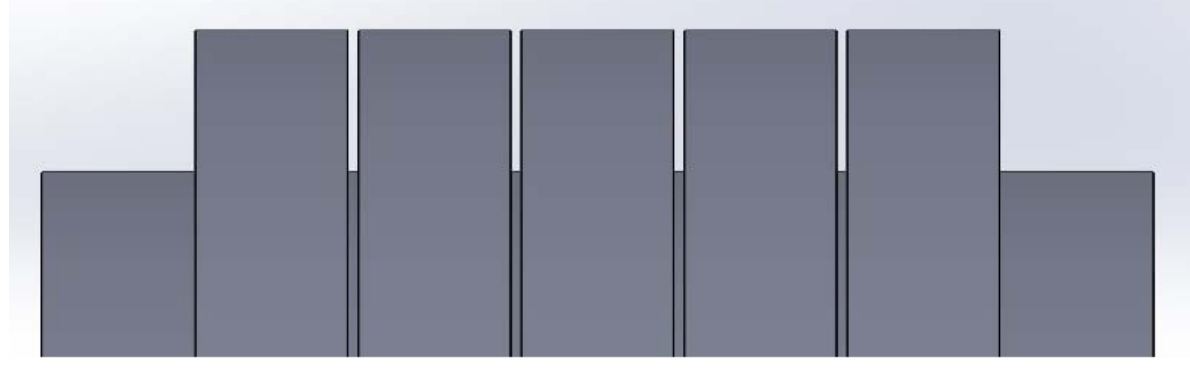

Fig. 3. 2D view of circumferentially-grooved labyrinth seal

\section{B. Mesh independant study}

In this study, different models have been meshed using mixed cells for each eccentricity ratio. The meshing was performed using ICEM in FLUENT. The number of elements in the meshed models for both the labyrinth seals varied from 70,000 to 2,40,000. With increase in number of elements the computational time increases. For a particular eccentricity ratio, the leakage flow rate was calculated for the meshed models and compared. The meshed model having approximately 1,40,000 elements is choosen for further analysis, since by meshing more than 1,40,000 number of elements the desired parameter (leakage flow rate at the exit) remains same. Fig. 4 shows the generated mesh of helically-grooved labyrinth seal.

\section{Simulation conditions}

The commercial finite volume CFD code FLUENT has been used to solve the incompressible Navier-Stokes equations. The pressure based solver model has been used for the simulation. Turbulence characteristics of the flow has been considered in the model by using k- $\varepsilon$ model. Scalable wall fuction as near wall treatment has been used to describe the near wall velocity. The algorithm used was SIMPLE algorithm with least square cell based gradient. Second order discretization scheme has been used for both pressure and momentum. The simulation input parameters are given in the following Table I. The labyrinth seal considered in this work is compressor eye labyrinth seal with air as the working fluid. Similar simulation conditions have been considered for the circumferentially-grooved seal as it was taken for the helically-grooved seal.

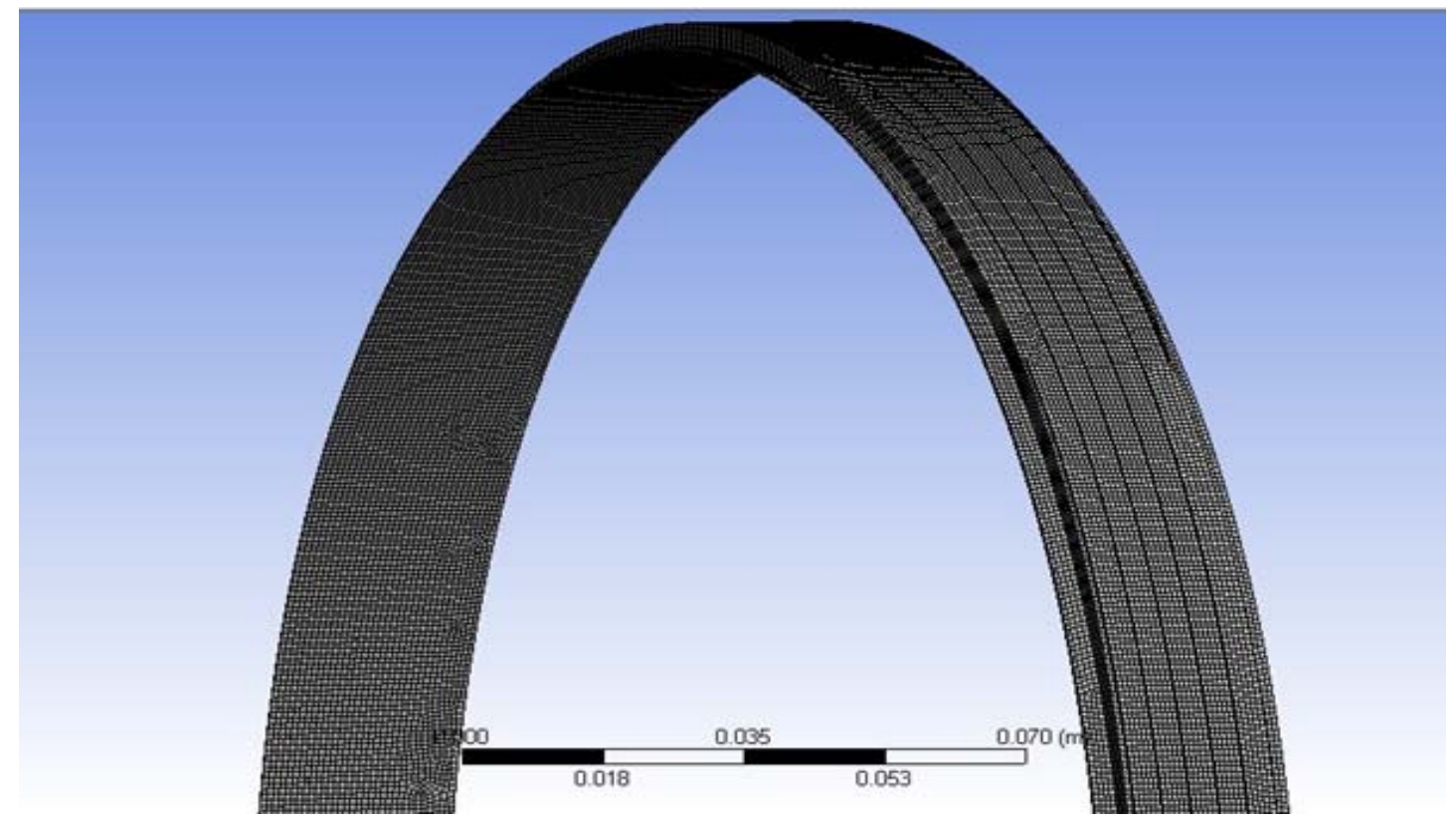

Fig. 4. Meshing of the model 
TABLE I: Simulation of Input Parameters

\begin{tabular}{|l|l|}
\hline Parameter & Value \\
\hline Rotor Diameter & $274.8 \mathrm{~mm}$ \\
\hline No. of teeth & 5 \\
\hline Rotation Speed & $10000-16000$ r.p.m \\
\hline Inlet Pressure & $3.345 \mathrm{MPa}$ \\
\hline Outlet Pressure & $1.622 \mathrm{MPa}$ \\
\hline Tempreature & $288.16 \mathrm{~K}$ \\
\hline
\end{tabular}

\section{Calculation of rotordynamic coefficients}

As stated earlier the presence of force introduces some dynamic characteristics, since the fluid (air) in between the stator and rotor acts as a spring-damper like structure. From the calculated pressure data from the simulation, it is possible to calculate the fluid forces in radial $\left(F_{r}\right)$ and tangential $\left(F_{t}\right)$ directions. Using these forces, the dynamic characteristics such as stiffness and damping coefficients can be calculated. These are calculated by using the following equations.

$$
\begin{gathered}
\frac{F_{r}}{e}=-K-\Omega C \\
\frac{F_{t}}{e}=k-\Omega C
\end{gathered}
$$

In this work, the rotor has been assumed to rotate in clockwise direction and this generates pressure forces within the region of fluid between the seal and the rotor. The model is suitably aligned such that $\mathrm{x}, \mathrm{y}$ and $\mathrm{z}$ directions correspond to the axial, radial and tangential directions respectively.

The equation of motion for labyrinth seal can be written as

$$
\left[\begin{array}{cc}
K & k \\
-k & K
\end{array}\right]\left\{\begin{array}{l}
x \\
y
\end{array}\right\}+\left[\begin{array}{cc}
C & c \\
-c & C
\end{array}\right]\left\{\begin{array}{l}
\dot{x} \\
\dot{y}
\end{array}\right\}=-\left\{\begin{array}{l}
F_{t} \\
F_{r}
\end{array}\right\}
$$

where, $x$ and $y$ are the displacements of rotor centre in $x$ and $y$ directions respectively. Similarly, $\dot{x}$ and $\dot{y}$ are the velocities of rotor centre in $x$ and $y$ directions respectively.

Radial force to eccentricity ratio can be calculated and plotted with rotor speed. According to the equation (1), intercept and slope of the straight line from the plot are the direct stiffness $(\mathrm{K})$ and cross-coupled damping coefficient (c). Similarly, tangential force to eccentricity ratio can be calculated and plotted with rotor speed. According to the equation (2), intercept and slope of the straight line from the plot are the cross-coupled stiffness $(\mathrm{k})$ and direct damping coefficient $(\mathrm{C})$. In this case, the whirling speed $(\Omega)$ is assumed to be the same as the spinning speed of the rotor $(\omega)$. Also positive whirling is assumed which means both the rotor spinning speed and the whirling speed directions are same. The plots have been shown in Fig. 5.

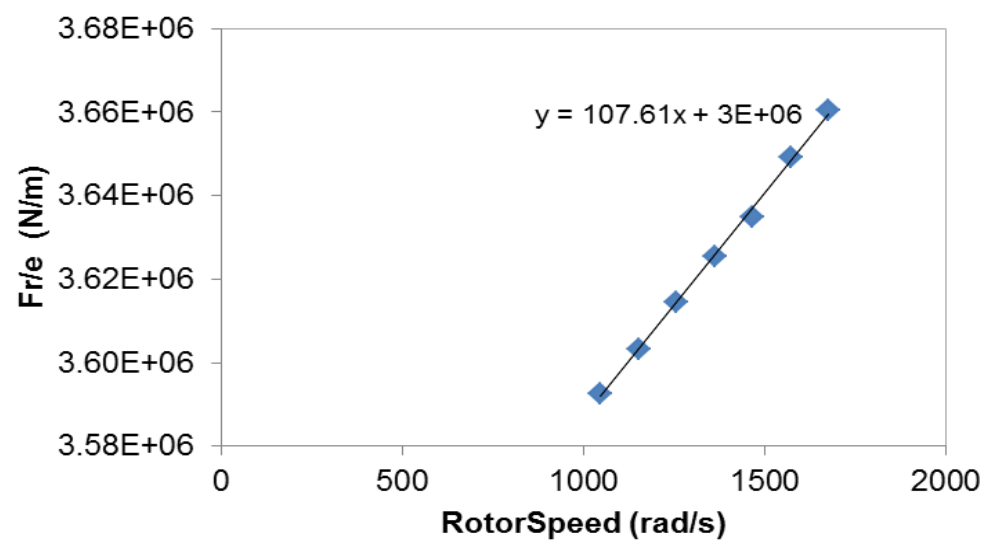

(a) 


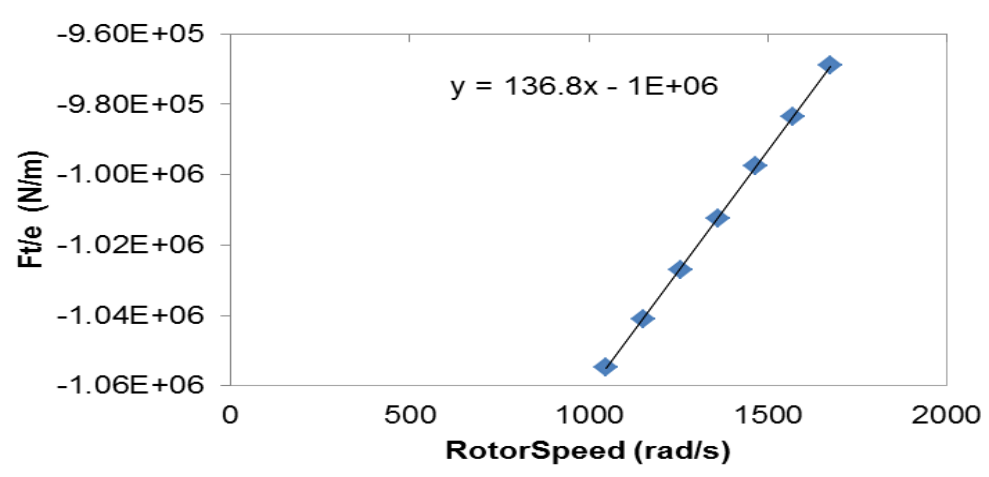

(b)

Fig. 5. Seal forces versus rotor speed in (a) Radial direction (b) Tangential direction

\section{RESULTS}

\section{A. Leakage}

Primary function of a labyrinth seal is to control the leakage and hence it is considered as the most important parameter. Fig. 6 shows the variation of leakage with rotor speed for helically-grooved labyrinth seals with different eccentricity ratios. The leakage increases with increase in rotor speed. From the plot it is also found that the leakage reduces with increase in eccentricity ratio, except for the model with eccentricity ratio of 0.68 .

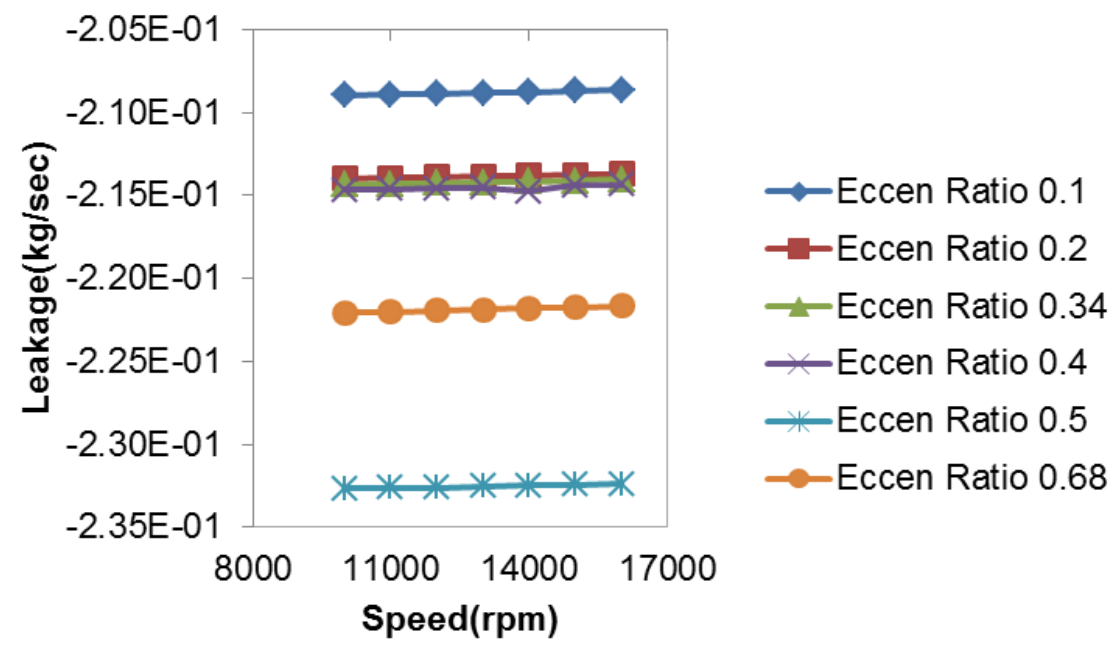

Fig. 6. Leakage vs speed for helically-grooved labyrinth seal

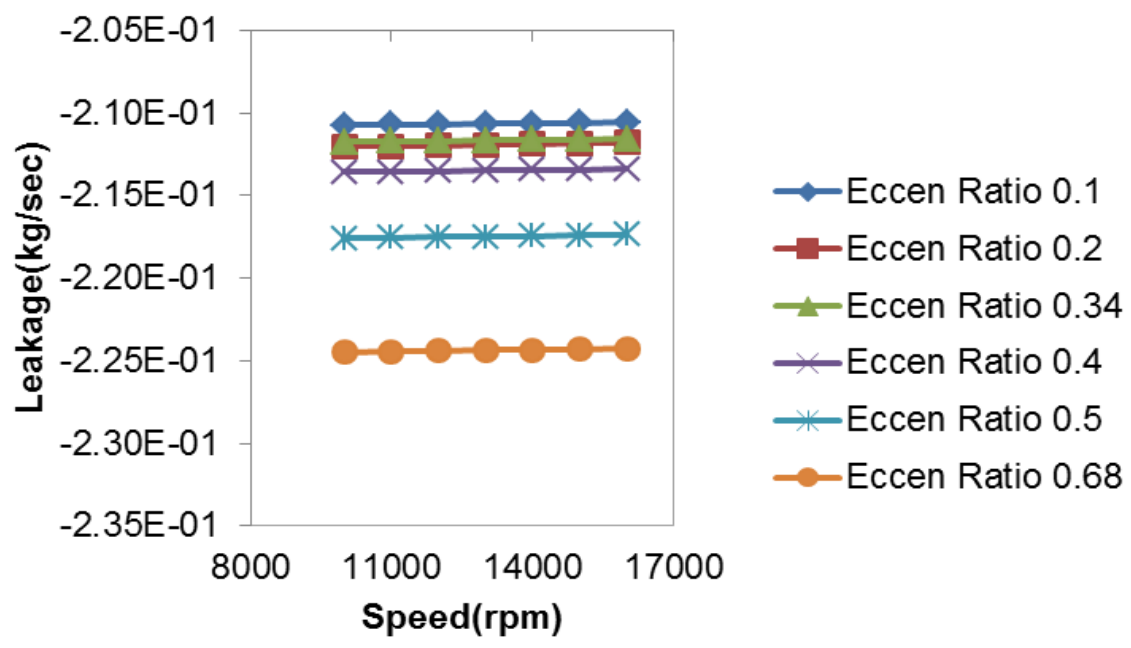

Fig. 7. Leakage vs speed for circumferentially-grooved labyrinth seal 
Fig. 7 shows the variation of leakage with rotor speed for circumferentially-grooved labyrinth seals with different eccentricity ratios. The leakage increases with increase in rotor speed. But the leakage reduces with increase in eccentricity ratio, except for the model with eccentricity ratio 0.34 .

The predicted amount of leakage is comparatively higher for a helically-grooved labyrinth seal than a circumferentially-grooved labyrinth seal with all eccentricity ratios except for 0.68 . But the difference of leakage between these two seals ranges from 0.01 to $0.15 \mathrm{~kg} / \mathrm{s}$. For the helically-grooved labyrinth seal, the predicted leakage is less than the circumferentially-grooved labyrinth seal by an amount of $0.02 \mathrm{~kg} / \mathrm{s}$.

\section{B. Radial Forces}

As the rotor is offset from the centre of stator, the fluid within the gap induces radial and tangential forces. Radial forces displace the rotor in the radial direction. Fig. 8 shows the variation of radial force with rotor speed for various eccentricity ratios in case of helically-grooved labyrinth seal. The Radial forces increase with increase in rotor speed, except for the eccentricity ratio 0.1 for which it remains constant. But with increase in eccentricity ratio, the radial force increases except for eccentricity ratio 0.5 .

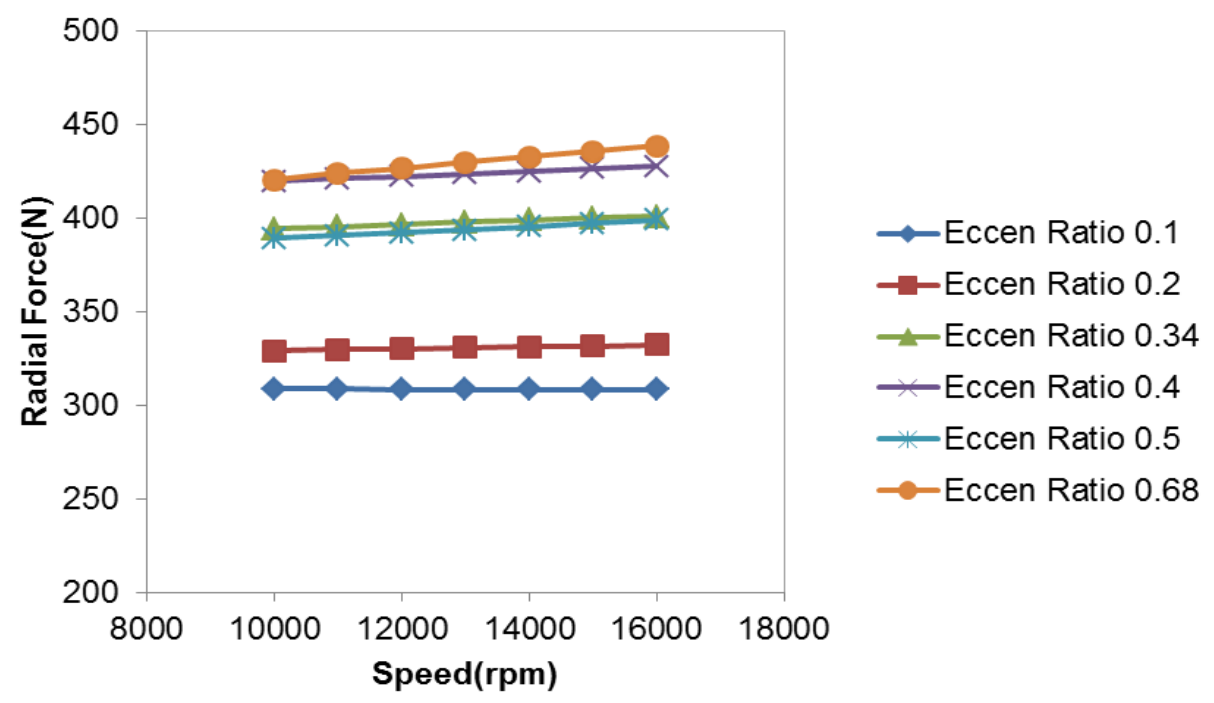

Fig. 8. Radial forces vs speed for helically-grooved labyrinth seal

Fig. 9 shows the variation of radial force with rotor speed for various eccentricity ratios in case of circumferentially-grooved labyrinth seal. For a particular eccentricity ratio, the radial forces increase with increase in speed. For a particular rotor speed, with increase in eccentricity ratio the radial force increases. The predicted value of radial force for helically-grooved labyrinth seal is more than that of circumferentiallygrooved labyrinth seal.

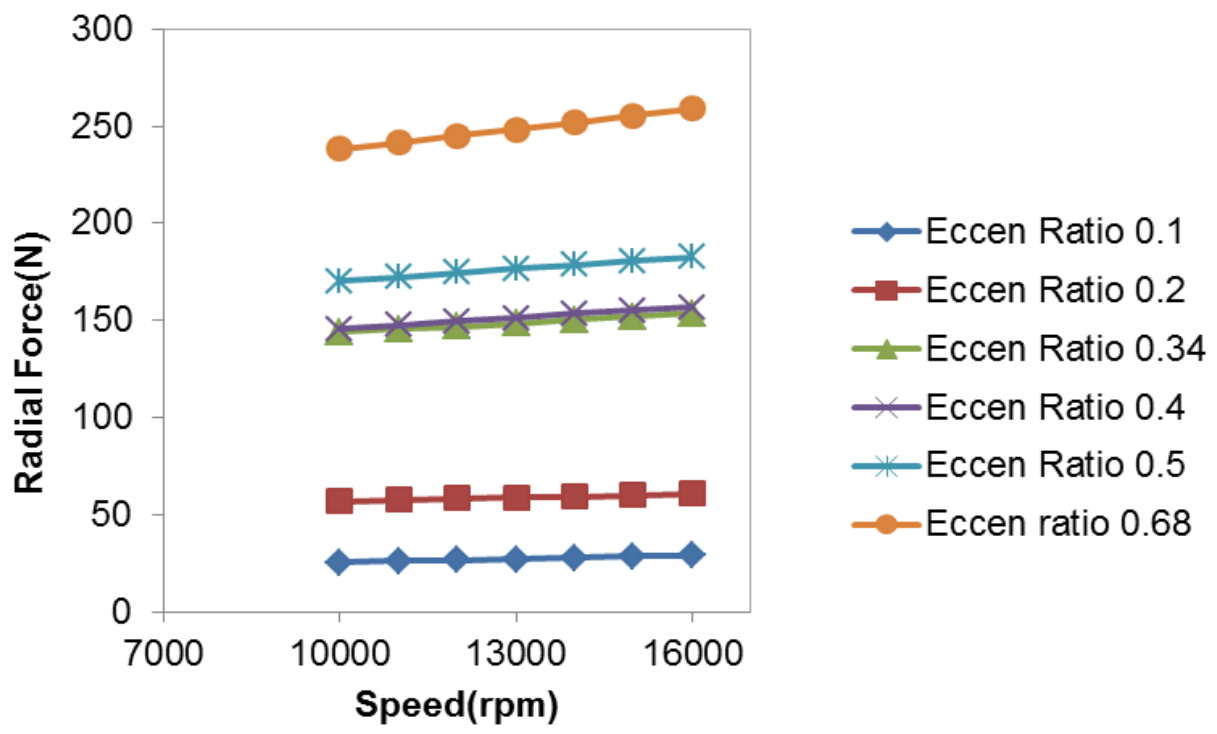

Fig. 9. Radial force vs speed for circumferentially-grooved labyrinth seal 


\section{Tangential Forces}

For helically-grooved labyrinth seal, the variation of the tangential forces with rotor speeds for various eccentricity ratios has been shown in the Fig. 10 The tangential forces increase with increase in speed except for the case of eccentricity ratio 0.1 for which it remains constant. For a particular rotor speed, with increase in eccentricity ratio the tangential forces decreases excluding for the case of eccentricity ratio 0.68 .

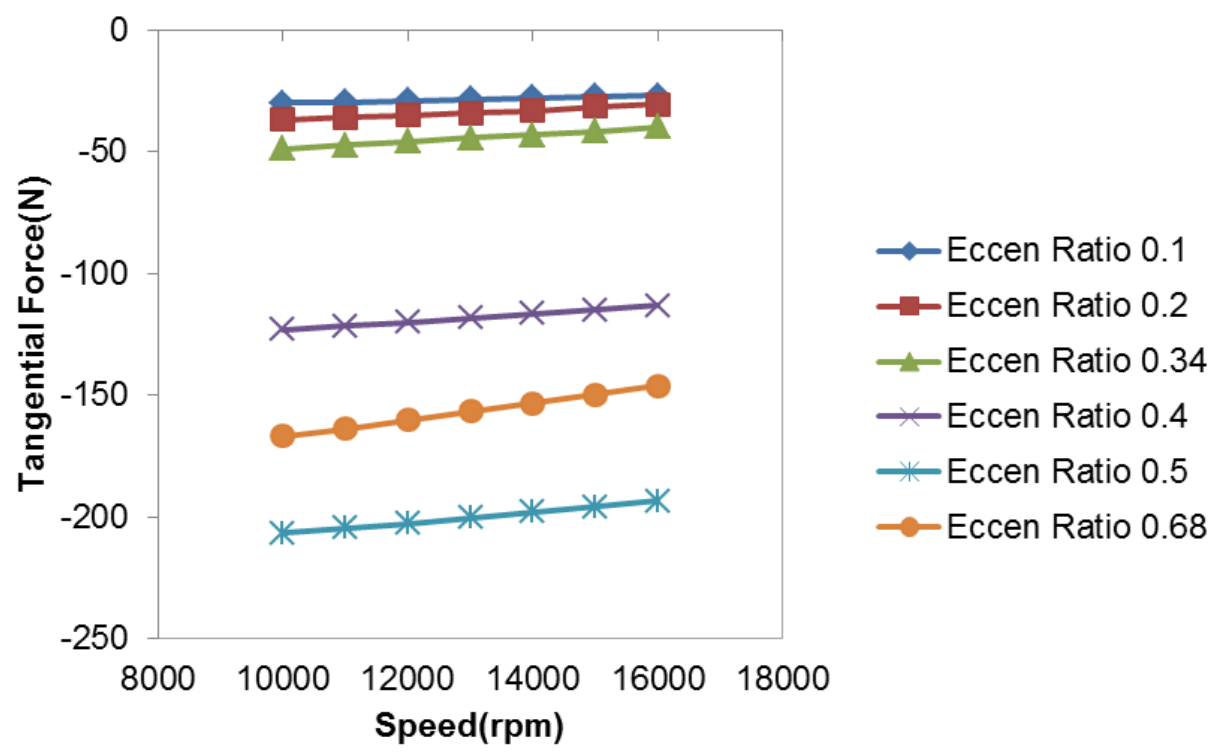

Fig. 10. Tangential force vs speed for helically-grooved labyrinth seal

For circumferentially-grooved labyrinth seal, the variation of the tangential forces with rotor speed for various eccentricity ratios are shown in the Fig. 11. The tangential forces increase with increase in rotor speed. For a particular rotor speed, with increase in eccentricity ratio the tangential forces increases excluding for the case of eccentricity ratio 0.68 .

Tangential force acts as a destabiliser pushes the shaft away from the centre. In order to stabilise the rotor, the magnitude of the tangential force should to be low. For eccentricity ratios less than 0.4 , the tangential force for helically-grooved labyrinth seal is less as compared to that of circumferentially-grooved labyrinth seal. But for eccentricity ratios more than 0.4 , the tangential force is more for the helically-grooved than the circumferentially-grooved labyrinth seal.

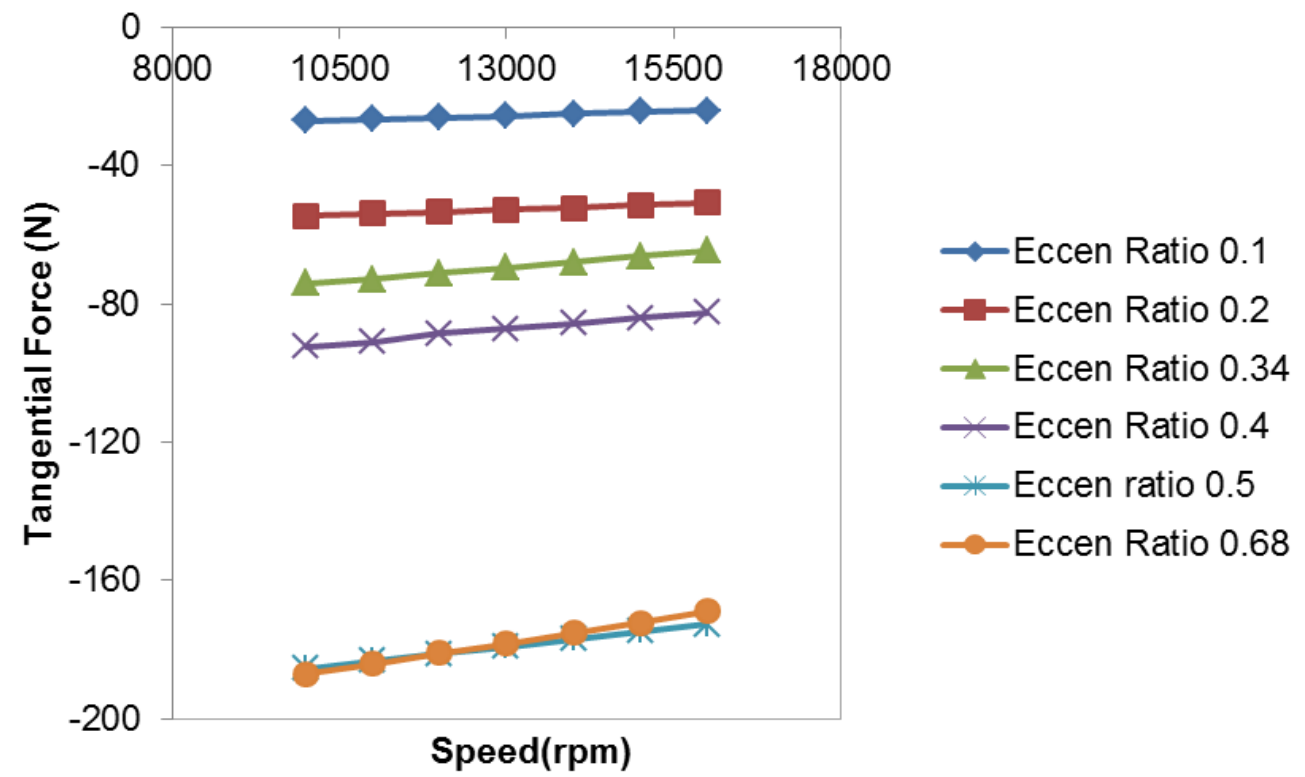

Fig. 11. Tangential force vs speed for circumferentially-grooved labyrinth seal 


\section{Dynamic Characteristics}

Predicted values of dynamic characteristics (stiffness and damping coefficients) for helically-grooved labyrinth seal have been obtained by using the Eqs. (1-2) mentioned in section II and their values are presented in Table II. The direct stiffness $(K)$ has a negligible influence over the stability of the rotor system. Crosscoupled stiffness coefficient $(k)$ has a direct impact over the stability of the rotor system. From Table II it is clear that all the values of $k$ are negative that tends to act in a direction to destabilize the system. Direct damping coefficient $(C)$ has a direct impact over the stability of the rotor system and it remains positive for all the eccentricity ratios indicating stable system. The value of cross-coupled damping $(c)$ is negative for eccentricity ratio 0.1 and is positive for other values of eccentricity ratios. The impact of cross-coupled damping coefficient (c) over the stability of the system is less.

TABLE II: Dynamic Coefficients for Varying Eccentricity Ratios of Helically-grooved Labyrinth Seal

\begin{tabular}{|c|c|c|c|c|}
\hline $\begin{array}{c}\text { Eccentricity } \\
\text { Ratio }\end{array}$ & $\begin{array}{c}\text { Direct Stiffness } \\
\text { K (N/m) }\end{array}$ & $\begin{array}{c}\text { Cross-Coupled } \\
\text { Stiffness k (N/m) }\end{array}$ & $\begin{array}{c}\text { Direct Damping } \\
\mathbf{C}(\mathbf{N s} / \mathbf{m})\end{array}$ & $\begin{array}{c}\text { Cross-Coupled } \\
\text { Damping c (Ns/m) }\end{array}$ \\
\hline 0.1 & $1.00 \mathrm{E}+07$ & $-1.00 \mathrm{E}+06$ & $1.71 \mathrm{E}+02$ & $-1.75 \mathrm{E}+01$ \\
\hline 0.2 & $6.00 \mathrm{E}+06$ & $-8.17 \mathrm{E}+05$ & $1.74 \mathrm{E}+02$ & $3.40 \mathrm{E}+01$ \\
\hline 0.34 & $4.00 \mathrm{E}+06$ & $-6.34 \mathrm{E}+05$ & $1.40 \mathrm{E}+02$ & $1.08 \mathrm{E}+02$ \\
\hline 0.4 & $3.00 \mathrm{E}+06$ & $-1.00 \mathrm{E}+06$ & $1.37 \mathrm{E}+02$ & $1.08 \mathrm{E}+02$ \\
\hline 0.5 & $3.00 \mathrm{E}+06$ & $-2.00 \mathrm{E}+06$ & $1.45 \mathrm{E}+02$ & $1.08 \mathrm{E}+02$ \\
\hline 0.68 & $2.00 \mathrm{E}+06$ & $-1.00 \mathrm{E}+06$ & $1.64 \mathrm{E}+02$ & $1.42 \mathrm{E}+02$ \\
\hline
\end{tabular}

The dynamic characteristics for circumferentially-grooved labyrinth seal have been obtained using the Eqs. (1-2) mentioned in the previous section II(D) and their values are presented in the Table III. This seal induces comparatively less direct stiffness $(K)$ values than that of helically-grooved seal. Like helically-grooved labyrinth seal, for circumferentially-grooved the values of cross-coupled stiffness $(k)$ are all negative are approximately of same order. Both direct damping coefficient $(C)$ and cross-coupled damping coefficient $(c)$ have positive values, hence the system is stable.

TABLE III: Dynamic Coefficients for Varying Eccentricity Ratios of Circumferentially-grooved Labyrinth Seal

\begin{tabular}{|c|c|c|c|c|}
\hline $\begin{array}{c}\text { Eccentricity } \\
\text { Ratio }\end{array}$ & $\begin{array}{c}\text { Direct Stiffness } \\
\text { K(N/m) }\end{array}$ & $\begin{array}{c}\text { Cross-Coupled } \\
\text { Stiffness k(N/m) }\end{array}$ & $\begin{array}{c}\text { Direct Damping } \\
\mathbf{C}(\mathbf{N s} / \mathbf{m})\end{array}$ & $\begin{array}{c}\text { Cross-Coupled } \\
\text { Damping c(Ns/m) }\end{array}$ \\
\hline 0.1 & $6.59 \mathrm{E}+05$ & $-1.00 \mathrm{E}+06$ & $1.60 \mathrm{E}+02$ & $2.00 \mathrm{E}+02$ \\
\hline 0.2 & $8.71 \mathrm{E}+05$ & $-1.00 \mathrm{E}+06$ & $1.04 \mathrm{E}+02$ & $9.84 \mathrm{E}+01$ \\
\hline 0.34 & $1.00 \mathrm{E}+06$ & $-9.04 \mathrm{E}+05$ & $1.53 \mathrm{E}+02$ & $1.53 \mathrm{E}+02$ \\
\hline 0.4 & $1.00 \mathrm{E}+06$ & $-9.32 \mathrm{E}+05$ & $1.35 \mathrm{E}+02$ & $1.54 \mathrm{E}+02$ \\
\hline 0.5 & $1.00 \mathrm{E}+06$ & $-1.00 \mathrm{E}+06$ & $1.39 \mathrm{E}+02$ & $1.37 \mathrm{E}+02$ \\
\hline 0.68 & $1.00 \mathrm{E}+06$ & $-1.00 \mathrm{E}+06$ & $1.43 \mathrm{E}+02$ & $1.65 \mathrm{E}+02$ \\
\hline
\end{tabular}

\section{IV.CONCLUSIONS}

In this work two labyrinth seals of different configurations (helically-grooved and circumferentially-grooved) have been modelled and simulated using CFD. The main conclusions have been pointed out below.

- The predicted leakage for helically-grooved is more than the circumferentially-grooved labyrinth seal.

- The range of variation of magnitude of radial force is comparatively higher for helically-grooved seal compared to circumferentially-grooved seal. But the Range of variation of magnitude of tangential force is almost same for both. 
- Magnitude of direct stiffness $(\mathrm{K})$ is higher for helically-grooved seal as compared to circumferentiallygrooved seal.

- For both the labyrinth seals the cross-coupled stiffness $(\mathrm{k})$ is negative and hence the system is not stable for these values. For circumferentially-grooved seal the value of $\mathrm{k}$ is almost independent of eccentricity ratio.

\section{REFERENCES}

[1] K. Willenborg, S. Kim and S. Wittig, Effects of Reynolds number and pressure ratio on leakage loss and heat transfer in a stepped labyrinth seal, Journal of Turbomachinery, Vol. 123, p. 815-822, 2011.

[2] A. Gamal and J. M. Vance. Labyrinth seal leakage tests: tooth profile, tooth thickness and eccentricity effects, Journal of Engineering for Gas Turbine and Power, Vol. 130, 012510-012520, 2008.

[3] T. S. Kim and K. S. Cha. Comparative analysis of the influence of labyrinth seal configuration on leakage behaviour, Journal of Mechanical Sceince and Technology, Vol. 23, p. 2830-2838, 2009.

[4] M. Wensheng, L. Zhusheng and C. Zhaobo. Study of leakage and stability in labyrinth seal using CFD, International Conference on Electronic and Mechanical Engineering and Information Technology, p. 588-591, 2011.

[5] M. Zhang, X. Wang, S. Xu and S. Yin. Leakage characteristic of helical groove seal designed in reactor coolant pump, International Journal of Rotating Machinery, Article ID 619459, p. 1-8, 2012.

[6] W. F. Zhang, J. G. Yang, C. Li and Y. W. Tian. Comparison of leakage performance and fluid-induced force of turbine tip labyrinth seal and a new kind of radial annular seal, Computers and Fluids, Vol. 105, p. 125-137, 2014.

[7] K. L. Chakravarthy and P. Srikanth. Modelling and analysis of labyrinth seals used in steam turbines, International Journal Science and Research, Vol. 4, p. 1808-1813, 2015.

[8] D. W. Childs, D. A. Elrod and K. Hale. Rotordynamic coefficient and leakage test results for interlock and tooth-on-stator labyrinth seals, Gas Turbines Aero engine Congress, Amsterdam, 1988

[9] D. Eser, J. Y. Kazakia. Air flow in cavities of labyrinth seals. International Journal of Enginerring Science, Vol. 33, No. 15, p. 2309$2326,1995$.

[10] D. Eser. Rotordynamic coefficients in stepped labyrinth seals, Computer Methods in Applied Mechanics and Engineering, Vol. 191, p. $3127-3135,2002$.

[11] T. Hirano, Z. Guo and R. G. Kirk. Application of CFD Analysis for rotating machinery, part 2: labyrinth seal analysis, Journal of Engineering for Gas Turbine and Power, Vol. 127, p. 820-826, 2005.

[12] S. P. Ashok, K. Sankaranarayanasamy, T. Sundararajan, G. Vaidyanathan and K. UdhayaKumar. Pressure drop and cavitation investigations on static helical-grooved square, triangular and curved cavity liquid labyrinth seals, Nuclear Engineering and Design, Vol. 241, p. 843-853, 2011.

[13] A. O. Pugachev and M. Deckner. Experimental and theoretical rotordynamic stiffness coefficients for a three-stage brush seal, Mechanical System Signal Processing, Vol. 31, p. 143-154, 2012.

[14] A. Untaroiu, D. C. Untaroiu, G. H. Wood and E. P. Allaire. Numerical modelling of fluid-induced rotordynamic forces in seals with large aspect ratios. Journal of Engineering for Gas Turbine and Power, Vol. 135, p. 012501-7, 2013.

[15] N. J. Mehta and D. W. Childs. Measured comparison of leakage and rotordynamic characteristics for a slanted-tooth and a straighttooth labyrinth seal, Journal of Engineering for Gas Turbine and Power, Vol. 136, No. 1, p. 012501-12511, 2014.

[16] T. Woong Ha and B. S. Choe. Numerical prediction of rotordynamic coefficients for an annular-type plain-gas seal using 3D CFD analysis, Journal of Mechanical Science and Technology, Vol. 28, No. 2, p. 505-511, 2014.

[17] Z. Li, J. Li and Z. Feng. Numerical comparison of rotordynamic characteristics for a fully-partitioned pocket damper seal and a labyrinth seal with high positive and negative inlet preswirl, Journal of Engineering for Gas Turbine and Power, Vol. 138, No. 4, p. $042505-42515,2015$

\section{AUTHOR PROFILE}

Kishore Kumar L graduated in 2013 from Governement College of Engineering, Salem in India with a first class Degree in Mechanical Engineering. He Acquired Master's Degree in 2016 with specialization in $\mathrm{CAD} / \mathrm{CAM}$ at VIT University, Vellore. His research area is computational fluid dynamics.

Dr. Niranjana Behera graduated in 1998 from VSSUT University, Burla in India with a first class degree in Mechanical Engineering. He first worked as a lecturer in MITS, Rayagada, Orissa, India. He undertook M.Tech programme at IIT, Kharagpur with specialization Mechanical system Design in 2004. After M.Tech he worked in JITM, Paralakhemundi, Orissa, India and ITER, Bhubaneswar, Orissa, India. He obtained PhD degree from IIT Delhi. In 2009 he visited University of Newcastle, Australia for six months to carryout experimental work on pneumatic conveying. Presently he is working as Associate Professor at VIT University, Vellore (India). 